\title{
Throughput efficiency and service quality after process redesign at a cancer daycare unit: Two sides of the same coin?
}

\begin{abstract}
Objective: This study was designed to focus on the patient perspective in a reorganization of care processes at a cancer daycare unit (CDU). The effects of dose banding and of taking blood samples one day (or more) before the daycare treatment (on day -1) is investigated in terms of throughput efficiency and perceived service quality.

Methods: Data were collected by mapping patient processes in detail and surveying patients in two CDUs at a university hospital $(\mathrm{n}=308)$. A univariate model was used to investigate the effect of these factors on patient throughput time, and perceived service quality was examined with multiple linear regression.

Results: Taking blood samples on day -1 decreases patient throughput time and increases the perceived service quality by improving the patient's perception of technical expertise and the outcome. This has a globally positive effect on patients' perceived service quality. Dose banding affected neither patient throughput time nor perceived service quality.

Conclusion: Taking the pretreatment blood sample on day -1 can be considered an important process design characteristic, as it increases both efficiency and service quality.
\end{abstract}

\section{Keywords}

Cancer care facilities; Efficiency; Service quality; Process (re)design ; Organisational; Outpatient clinics 


\section{Introduction}

There has been a considerable shift in cancer care from inpatient admissions to more outpatient visits and ambulatory care (Berglund, Gustafsson, Johansson \& Bergenmar, 2015). This results in a higher number of patients being treated in daycare and highlights the need for increased timeliness and efficiency at cancer daycare units (CDUs). As a result, concepts such as lean and business process management are making their way into the sector (D’Andreamatteo, Ianni, Lega \& Sargiacomo, 2015; Manfreda, Kovacic, Štemberger \& Trkman, 2014). These studies have led to several suggestions for improvement, such as collecting the blood samples during an outpatient visit one or more days before the daycare treatment (day -1), in order to prepare the anticancer medication in advance. This leads to a reduction in patient throughput time in the CDU on the day of treatment (day 0) and increases the number of patients that can be treated per day (van Lent, Goedbloed \& Van Harten, 2009). Another approach to reducing throughput time is dose banding (Huertas et al., 2015; Masselink, van der Mijden, Litvak \& Vanberkel, 2012), which refers to a method that uses predefined ranges (bands) of body surface area (BSA) to calculate each patient's dose as a single BSA value per band. This principle can only be applied to drugs with sufficient long-term stability. Dose banding and taking the blood sample on day -1 can both be considered process redesign initiatives.

Despite the growing recognition and acceptance of the need to embrace patient-centred care approaches (Masselink et al., 2012), healthcare studies have paid limited attention to the patient perspective in process redesign initiatives (Moraros, Lemstra \& Nwankwo, 2016). Most studies have focused merely on the collection of operational metrics, such as patient throughput time and the number of operational failures (McIntosh, Sheppy \& Cohen, 2014), but have neglected 'the patient's perspective' as a measure. This study instead aims to integrate the patient perspective into the operational analysis and design of hospital processes in cancer care. 
The objective of this study is to measure the effect of dose banding and taking the blood sample on day -1 in two CDUs on both the throughput efficiency of the department and on the service quality perceived by patients. The efficiency will be studied by examining throughput time from the arrival of the patient in the CDU to the initiation of therapy. The perceived service quality is examined by means of a patient survey investigating patients' opinion of the service quality of the department. This study investigates whether this process redesign at the CDU results in an improved service quality as perceived by the patient.

\section{Method}

\section{Procedure}

Data were collected during one week in April $2015(\mathrm{n}=163)$ and one week in November $2015(\mathrm{n}=145)$ at two CDUs in a university hospital. The study was approved by the medical ethics committee. Observations, document analysis, and six semistructured interviews were carried out in order to develop a process travel sheet for each department. Each patient process was documented by filling out the process travel sheet. CDU staff and the hospital pharmacy collected time and process data on each patient. Patients filled out a survey coupled to the process travel sheets in order to collect data from the patient perspective. Data from 780 patient processes were gathered. Data from the survey was available for $40 \%$ of these processes, as patients visited the clinic twice, and left out data in the responses.

\section{Measures}

The process travel sheet followed the patient process in the CDU to collect data on time points in the treatment process (e.g., arrival in the department, contact with the physician, and initiation of treatment). The travel sheet also identified whether the patient's blood sample was taken on day -1 or on day 0 . Data related to the process of anticancer drug preparation at the pharmacy were also collected and allowed us to identify whether dose banding was used. Other variables gathered on the process travel sheets were the CDU, the cancer type, and the type of 
medication. The service quality scale of Dagger et al. (2007) was used to record the perception of patients. Perceptions of four service quality dimensions (see Figure 1) were measured by means of a seven-point Likert scale (Dagger et al., 2007): Interpersonal quality reflects the interaction and the relationship over time between the service provider and the patient. Technical quality covers the professional competences of the service providers and the outcome. Environmental quality defines the complex mix of environmental features that shape the perceptions of patients, such as the atmosphere. Administrative quality relates to the supporting nonclinical and clinical services that facilitate the delivery of the core service.

Figure 1: Dimensions of service quality, based on Dagger et al. (2007)

Insert Figure 1 about here

\section{Statistical Analysis}

Since the data were not normally distributed (Kolmogorov-Smirnoff test: $p<0.05$ ), a $\log$ transformation was performed for patient throughput time and perception variables were centralized. The validity of the constructs was assessed using confirmatory factor analysis. The measurement model for the sample performed well without the operational subdimension. The sample showed convergent validity and adequate construct validity. Since the measurement model performed well, in the further analysis we used mean scores for interpersonal quality, technical quality, environmental quality, administrative quality, and the perceived service satisfaction in relation to the CDU.

The effect of the new process characteristics (dose banding and taking the blood sample on day -1) on waiting time was statistically evaluated using a general univariate linear model 
with the univariate GLM dialog (Levene's test: $\mathrm{p}=.148$ ) with the factors dose banding (two factors) and day of blood sample (two factors). The effect of the quality dimensions of service quality and redesign characteristics on perceived service quality were analysed using multiple linear regression.

\section{Results}

The descriptive results show a difference in population between the two departments (see Table 1). In $14.9 \%$ of processes, medication was prepared by dose banding, and in $41.9 \%$ of the cases the blood sample was taken on day -1. As shown in Table 2, significant relationships was observed between all quality dimensions and the perceived service quality. Only technical quality correlated with patient throughput time.

Table 1. Descriptive statistics

Insert Table 1 about here

Table 2. Internal consistency and the correlation matrix

Insert Table 2 about here

\section{Effect of redesign initiatives on patient throughput time}

Table 3. Patient throughput time

Insert Table 3 about here

The time of blood sampling had a significant effect on throughput time $(\mathrm{F}=32.859 ; \mathrm{p}$ 
$<0.001$; part. $\left.\mathrm{y}^{2}=.105\right)$. There was no significant effect of dose banding $(\mathrm{F}=.495 ; \mathrm{p}=.482$; part. $y^{2}=.002$; see Table 3). There was no interaction effect between the moment of blood sampling and dose banding $\left(\mathrm{F}=1.151 ; \mathrm{p}=.284 ;\right.$ part. $\left.\mathrm{p}^{2}=.004\right)$. The model explained $20.3 \%$ of the variance in the throughput time $\left(\mathrm{F}(5,281)=15.604 ; \mathrm{p}<.001 ;\right.$ part. $\left.\mathrm{y}^{2}=.217\right)$. The model was controlled for the time of data collection and for the department where the data was collected. No control variables were significant.

\section{Effect of redesign initiatives on service quality perception}

Based on the hierarchical analysis, the control variables (moment of data collection and department) showed no significance $\left(F(3,255)=2.278 ; \mathrm{p}=.079\right.$, Adj. $\left.\mathrm{R}^{2}=.02\right)$ and were not added to the model.

Table 4. Multiple linear regression

Insert Table 4 about here

We searched for the best-fitting model based on a significant $\mathrm{R}^{2}$ change (see Table 3 ). The model with only environmental quality, technical quality, and administrative quality as independent variables explained $62.9 \%$ of the variance in perceived service quality. This change in $\mathrm{R}^{2}$ became significant $(\mathrm{p}=.007)$ when the interaction of taking the blood sample on day -1 and technical quality was added. The final model explained $63.7 \%$ of the variance in perceived service quality. Technical quality is the most important quality dimension $(\mathrm{B}=.688)$, followed by administrative quality $(\mathrm{B}=.138)$, and environmental quality $(\mathrm{B}=.097)$. When the blood sample was taken on day -1 , the perceived service quality per unit change in technical quality was on average .263 higher than when the blood sample was not taken in advance. 


\section{Discussion}

The results of this study demonstrate the effect of process design characteristics on the efficiency and quality of an organization. Taking the blood sample on day -1 does significantly decrease patient throughput time before the initiation of therapy on day 0 . Throughput efficiency is thus increased and more patients can be treated per day at the department, which is an important performance measure for CDUs. This throughput time also includes waiting time for the patient, which has been identified in previous research as being not valuable for the patient and should thus be reduced (Masselink et al., 2012; Turkcan, Zeng \& Lawley, 2012; van Lent et al., 2009; Vanberkel et al., 2010).

On the other hand, dose banding has no significant effect on patient throughput time, although it has been identified as a strategy for accelerating in-hospital turnaround time for commonly used preparations that contribute to enhanced daily patient capacity in oncology clinics (Hoppe-Tichy, 2009). There are several reasons why dose banding does not lead to a reduction in patient throughput time, such as the fact that it is only possible for drugs with sufficient long-term stability; sometimes a mix of drugs with and without dose banding is used for patients who are receiving multiagent chemotherapy protocols. Nevertheless, dose banding does reduce throughput time in the pharmacy (Claus et al., 2018), improving organizational processes there, but so far the impact on the patient process in the CDU seems to be limited.

We also investigated the impact of the redesign characteristics on the perceived service quality of the patient. As such, our study contributes to the debate on how measurements of patients' perceptions helps understand the patient experience with regard to oncology processes. This is an important topic in the current discussion on patient reported experience measures (PREMs) (Luckett, Butow \& King, 2009). Most variance in perceived service quality was explained by technical quality. Environmental and administrative quality were also significant, but interpersonal quality surprisingly was not. This is not in line with the report of 
Dagger et al. (2007), who found that interpersonal quality had a significant effect on perceived service quality in a private outpatient oncology clinic. However, interpersonal and technical quality are both terms used to describe the competence of the medical staff. It may be that patients focus more on the technical quality than on the interpersonal quality on account of the setting. The study was carried out in a university hospital, which has more expertise in complex diseases and the administration of complex multiagent chemotherapy protocols. Because of the severity and complexity of the individual cases, patients may focus more on technical quality rather than interpersonal quality. As expected, dose banding did not influence the perceived service quality, as dose banding is an organizational issue that is not discussed with the patient prior to treatment, meaning the patient is not aware of whether dose banding is used to prepare the medication.

When a blood sample is taken on day -1 , the average increase in perceived service quality per unit change in technical quality is .202 greater than when the blood sample is not taken in advance. Although more effort is required of patients who must visit the hospital twice (or pay an additional visit to a general practitioner), it nonetheless affects the perception of technical quality positively. This might be explained by the fact that the blood sample is taken in a different professional environment. On day -1 , the patient is typically seen by a nurse and a physician who discuss the treatment experience in a more general way, without focusing exclusively on the administration of anticancer drugs. Hence, the individual time spent with a practitioner on at a separate point in time is valuable for a patient.

This study has several limitations. Our response rate (40\%) was not high, but is nonetheless reasonable, given the requirement that both the survey and process travel sheet needed to be filled out correctly. The study was performed at only two CDUs at a single university hospital. This rather small sample size restricts the interpretation and generalization of the results. The quantitative method to measure perceived service satisfaction gives less 
information about why patients perceive technical quality better when the blood sample is taken on day -1. A qualitative study could give more insight into this.

Despite its limitations, the results of this study highlight several key aspects that should be considered in the design of cancer care services. The implementation of dose banding might improve performance in the pharmacy department, but has no significant impact on the CDU. On the other hand, taking blood samples taken on day -1 has a positive effect on both the patient throughput time and the perceived service quality. The throughput time of an individual patient is thus reduced and more patients can be treated in a single day. Although taking the blood sample on day -1 requires an extra effort from the patients, who must visit a professional twice, this nonetheless increases the perceived service quality. In conclusion, the efficiency of the CDU and the service quality, as perceived by the patient, can be considered to be two sides of the same coin.

\section{References}

Berglund, C. B., Gustafsson, E., Johansson, H. \& Bergenmar, M. (2015). Nurse-led outpatient clinics in oncology care: Patient satisfaction, information and continuity of care. European Journal of Oncology Nursing, 19(6), 724-730.

Claus, B., De Pourcq, K., Clottens, N., Kruse, V., Gemmel, P. \& Vandenbroucke, J. (2018) The impact of logarithmic dose banding of anticancer drugs on pharmacy compounding efficiency at Ghent University Hospital. European Journal of Hospital Pharmacy published online.

D’Andreamatteo, A., Ianni, L., Lega, F. \& Sargiacomo, M. (2015). Lean in healthcare: A comprehensive review. Health Policy, 119(9), 1197-1209. 
Dagger, T. S., Sweeney, J. C. \& Johnson, L. W. (2007). A hierarchical model of health service quality scale development and investigation of an integrated model. Journal of Service Research, 10(2), 123-142.

Ferlay, J., Steliarova-Foucher, E., Lortet-Tieulent, J., Rosso, S., Coebergh, J. W. W., Comber, H. \& Bray, F. (2013). Cancer incidence and mortality patterns in Europe: Estimates for 40 countries in 2012. European Journal of Cancer, 49(6), 1374-1403.

Gill, L. \& White, L. (2009). A critical review of patient satisfaction. Leadership in Health Services, 22(1), 8-19.

Hoppe-Tichy, T. (2009). Current challenges in European oncology pharmacy practice. Journal of Oncology Pharmacy Practice, 16(1), 9-18.

Huertas, P. P., Sola, M. C., Cava, P. E., García, C. B., Marí, A. A., Briz, E. L. \& Andrés, J. L. P. (2015). Applying dose banding to the production of antineoplastic drugs: A narrative review of the literature. Farmacia Hospitalia, 39(4), 210-216.

IBM (2014). IBM SPSS Statistics for Windows, Version 23.0. Armonk, NY: IBM.

Luckett, T., Butow, P. N. \& King, M. T. (2009). Improving patient outcomes through the routine use of patient-reported data in cancer clinics: Future directions. PsychoOncology, 18(11), 1129-1138.

Manfreda, A., Kovacic, A., Štemberger, M. I. \& Trkman, P. (2014). Absorptive capacity as a precondition for business process improvement. Journal of Computer Information Systems, 54(2), 35-43.

Masselink, I. H., van der Mijden, T. L., Litvak, N. \& Vanberkel, P. T. (2012). Preparation of chemotherapy drugs: Planning policy for reduced waiting times. Omega, 40(2), 181187. 
McIntosh, B., Sheppy, B. \& Cohen, I. (2014). Illusion or delusion? Lean management in the health sector. International Journal of Health Care Quality Assurance, 27(6), 482492.

Moraros, J., Lemstra, M. \& Nwankwo, C. (2016). Lean interventions in healthcare: do they actually work? A systematic literature review. International Journal for Quality in Health Care, 28(2), 150-165.

Turkcan, A., Zeng, B. \& Lawley, M. (2012). Chemotherapy operations planning and scheduling. IIE Transactions on Healthcare Systems Engineering, 2(1), 31-49.

van Lent, W. A., Goedbloed, N. \& Van Harten, W. (2009). Improving the efficiency of a chemotherapy day unit: Applying a business approach to oncology. European Journal of Cancer, 45(5), 800-806.

Vanberkel, P. T., Boucherie, R. J., Hans, E. W., Hurink, J. L., Litvak, N., Lent, W. A. \& Harten, W. H. (2010). Reallocating resources to focused factories: a case study in chemotherapy. In J. Blake \& M. Carter (Eds.), Proceedings of the 34th Meeting of the European Group on Operations Research Applied to Health Services (pp. 52-164). Twente: ORAHS. 
Figure 1: Dimensions of service quality based on Dagger et al. (2007)

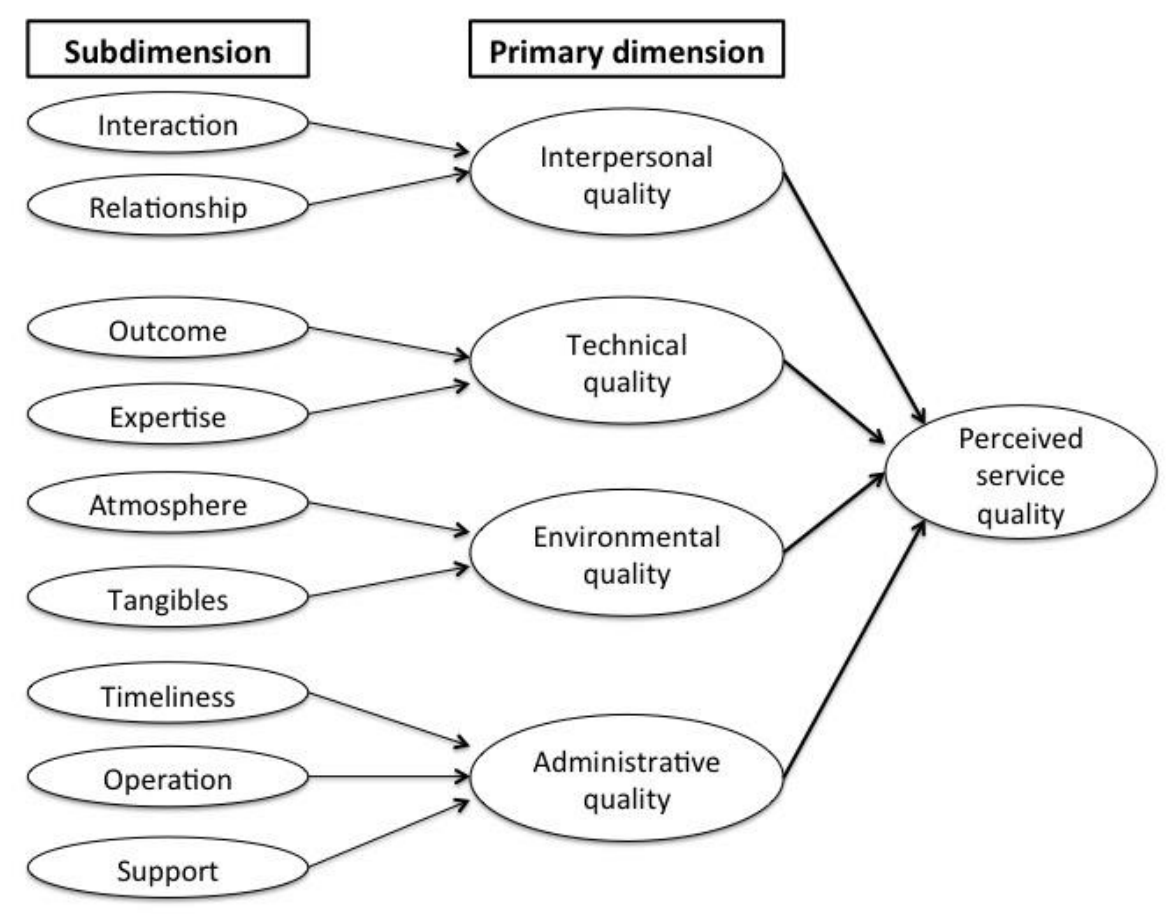

Legend Figure 1:

Illustration of the four dimensions and their subdimensions for evaluating perceived service quality. 
Table 1. Descriptive statistics

\begin{tabular}{|c|c|c|}
\hline & Frequency & Percentage \\
\hline \multicolumn{3}{|l|}{ Time of data collection } \\
\hline Time of data collection 1 & 163 & $52.9 \%$ \\
\hline Time of data collection 2 & 145 & $47.1 \%$ \\
\hline \multicolumn{3}{|l|}{ Department } \\
\hline CDU1 & 151 & $49.0 \%$ \\
\hline Breast cancer & 76 & $50 \%$ \\
\hline Head or neck cancer & 16 & $11 \%$ \\
\hline Pelvic cancer & 13 & $9 \%$ \\
\hline Gastroenterological cancer & 11 & $7 \%$ \\
\hline Melanoma & 10 & $7 \%$ \\
\hline Urological cancer & 9 & $6 \%$ \\
\hline Sarcoma & 2 & $1 \%$ \\
\hline Thoracic cancer & 1 & $1 \%$ \\
\hline Genetic disorder & 1 & $1 \%$ \\
\hline CDU2 & 157 & $51.0 \%$ \\
\hline Haematology & 66 & $42 \%$ \\
\hline Gastroenterological cancer & 78 & $50 \%$ \\
\hline Thoracic cancers & 13 & $8 \%$ \\
\hline \multicolumn{3}{|l|}{ Blood sample } \\
\hline Day 0 & 179 & $58.1 \%$ \\
\hline Day -1 & 129 & $41.9 \%$ \\
\hline \multicolumn{3}{|l|}{ Dose banding } \\
\hline Yes & 46 & $14.9 \%$ \\
\hline No & 262 & $85.1 \%$ \\
\hline
\end{tabular}


Table 2. Internal consistency and correlation matrix

\begin{tabular}{|c|c|c|c|c|c|c|c|c|}
\hline Constructs & $\mathbf{M}$ & SD & $\begin{array}{l}\text { Cronbach's } \\
\text { Alpha }\end{array}$ & 1 & 2 & 3 & 4 & 5 \\
\hline 1. Patient throughput time & $\begin{array}{c}1: 56: 30 \pm \\
0: 03: 49\end{array}$ & $1: 04: 47$ & NA & & & & & \\
\hline 2. Administrative quality & $5.34 \pm 0.06$ & 0.99 & .64 & .038 & & & & \\
\hline 3. Environmental quality & $4.94 \pm 0.07$ & 1.27 & .94 & .097 & $.491 *$ & & & \\
\hline 4. Interactional quality & $5.60 \pm 0.05$ & 0.86 & .70 & .089 & $.472 *$ & $.365 *$ & & \\
\hline 5. Technical quality & $6.11 \pm 0.04$ & 0.61 & .81 & $.121 *$ & $.519 *$ & $.399 *$ & $.577 *$ & \\
\hline 6 Perceived quality & $5.96 \pm 0.05$ & 0.80 & & .071 & $.564 *$ & $.489 *$ & $.494 *$ & $.749 *$ \\
\hline
\end{tabular}

Note. $\mathrm{M}=$ mean construct score (unweighted); $\mathrm{SD}=$ standard deviation; the diagonal numbers represent the correlations between constructs; $* p<.05$. 
Table 3. Patient throughput time

Throughput time

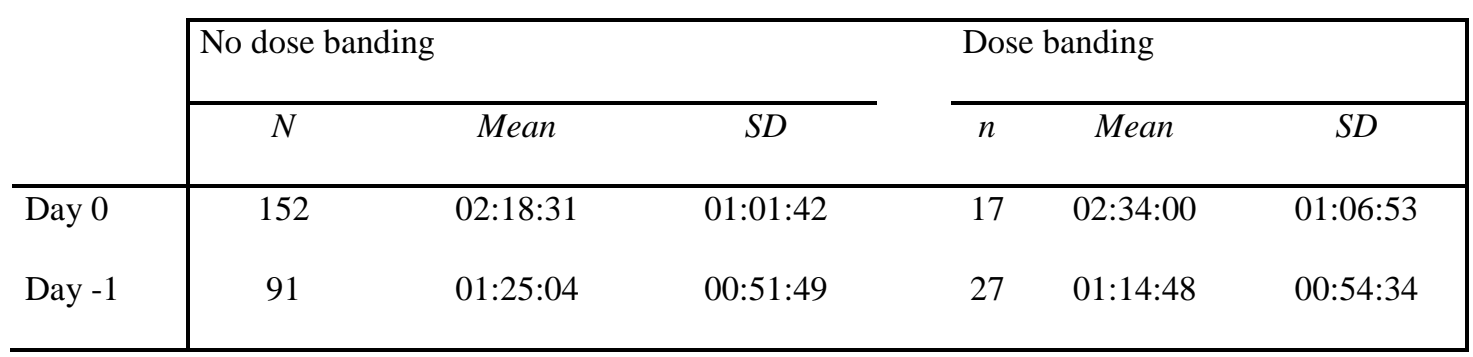

Legend: Throughput time related to day the blood sample was taken and the use of dose banding. $\mathrm{N}=$ number of participants; $\mathrm{SD}=$ Standard deviation 
Table 4. Multiple linear regression

\begin{tabular}{|lllllll|}
\hline & Variable & $\mathrm{b}$ & $\mathrm{SE}(\mathrm{b})$ & $\mathrm{t}$ & $\mathrm{p}$ & $\operatorname{Adj}^{2}$ \\
\hline Model 1 & & & & & $<0.001$ & 0.629 \\
& Environmental quality & 0.099 & 0.026 & 3.739 & $<0.001$ & \\
& Technical quality & 0.785 & 0.056 & 13.954 & $<0.001$ & \\
& Administrative quality & 0.140 & 0.036 & 3.865 & $<0.001$ & \\
Model 2 & & & & & & \\
& Environmental quality & 0.097 & 0.026 & 3.705 & $<0.001$ & 0.637 \\
& $\begin{array}{l}\text { Technical quality } \\
\text { Administrative quality }\end{array}$ & 0.688 & 0.066 & 10.438 & $<0.001$ & \\
& $\begin{array}{l}\text { Technical quality * Blood } \\
\text { sample }\end{array}$ & 0.138 & 0.036 & 3.847 & $<0.001$ & \\
\hline
\end{tabular}

Legend: The best fitting model based on a significant $\mathrm{R}^{2}$ was used to determine the most parsimonious model of perceived service quality. Model 1 evaluates administrative quality, technical quality and environmental quality as the independent variables and explained $63.6 \%$ of the variance in perceived service quality $(\mathrm{p}<0.001)$. Model 2 , also considering the interaction effect of technical quality and the day the blood sample was taken, explained $64.5 \%$ of the variance in perceived service quality with a significant $R 2$ change $(p=0.006)$. 